\title{
STOP-Bang Test Results of a Randomly Selected Group of Fibromyalgia Patients
}

\author{
Ilker Ilhanli ${ }^{1, ~ *}$, Necip Guder², Canan Celik ${ }^{1}$ \\ ${ }^{1}$ Department of Physical Medicine and Rehabilitation, School of Medicine, Giresun University, Giresun, Turkey \\ ${ }^{2}$ Physical Medicine and Rehabilitation State Hospital, Giresun, Turkey
}

\section{Email address:}

ilkerilhanli@hotmail.com (I. Ilhanli)

\section{To cite this article:}

Ilker Ilhanli, Necip Guder, Canan Celik. STOP-Bang Test Results of a Randomly Selected Group of Fibromyalgia Patients. American Journal of Clinical and Experimental Medicine. Vol. 4, No. 1, 2016, pp. 1-6. doi: 10.11648/j.ajcem.20160401.11

\begin{abstract}
Except for diffuse musculoskeletal pain and pain at tender points, the symptoms reported by patients with Obstructive sleep apnea syndrome (OSAS) are similar to those of patients with fibromyalgia syndrome (FMS). Patients with OSAS can also present FMS. STOP-Bang test is an effective scale which was developed to identify the patients with OSAS. The aim of this study was to evaluate the probable correlation between symptom severity of FMS and STOP-Bang test. Thirty one patients were included in the study. Demographic data including gender, age, body mass index and concomitant diseases are recorded. Musculoskeletal and neurologic examination, measurement of neck circumference and limitation of cervical range of motion were performed. Also MRI findings were recorded as decreased cervical lordosis, spondylosis and discopathy. STOP-Bang test was applied. Beside this test presence of snoring and fatigue were asked again separately. Fibromyalgia Impact Questionnaire (FIQ) was applied. Results of FIQ including total score, visual analog scale for pain (VAS pain) and fatigue (VAS fatigue) were recorded. Twenty five patients $(80,6 \%)$ were female and 6 patients $(19,4 \%)$ were male. Neck circumference of male patients was significantly higher than the females $(p<0,05)$. All patients were complaining of fatigue, and $61,3 \%$ reported snoring. According to the STOP-Bang test high risk of OSAS was found in 54,8\% of the patients (5 males and 12 females). There was significant and positive correlation between snoring and VAS pain, VAS fatigue, FIQ score and high risk of OSAS (p<0,01). Correlations between high risk of OSAS and VAS pain, VAS fatigue and FIQ score $(p<0,01)$ were significant, as well as the correlations between high risk of OSAS and limitation of cervical rotation, and presence of cervical discopathy and decreased cervical lordosis $(\mathrm{p}<0,05)$. Although it does not imply a cause and effect relationship, the association between FMS and OSAS is clear. Physicians should keep in mind the presence of OSAS among patients with FMS, especially in male patients. STOP-Bang test is an effective co-examination to predict the risk level of OSAS which is correlated with snoring. Only asking presence of snoring can substitute for STOP-Bang test to refer these patients for the examination of upper airways.
\end{abstract}

Keywords: Fibromyalgia Syndrome, Obstructive Sleep Apnea Syndrome, STOP-Bang, Snoring

\section{Introduction}

Fibromyalgia syndrome (FMS) is a rheumatic disease characterized by chronic widespread pain, tenderness and various symptoms including fatigue, sleep disorders, bowel dysfunction and headache [1]. Although a number of pathophysiologic factors such as genetics, psychosocial variables, environmental stressors and the neuroendocrineautonomic nervous system have been sorted, the etiology is still unknown [2, 3]. According to the American College of Rheumatology (ACR) criteria for FMS, widespread musculoskeletal pain and multiple tender points in specific anatomical sites are the key criteria for diagnosing FMS [1].
Although fatigue and sleep disturbances are not significant enough to differentiate patients with FMS from those with articular and connective tissue disease, subsequent clinical studies determined that the most commonly rated symptoms are unrefreshing sleep, morning stiffness, fatigue, pain, and problems with concentration and memory [4]. It is stated that inadequate sleep has a cumulative effect on negative affects and prevents affective recovery from days with a high number of negative events $[5,6]$.

Sleep-disordered breathing (SDB) is defined as obstructive breathing episodes occurring exclusively during sleep which is related to relaxation of the pharynx and the consequent increase in upper airway resistance [7]. The degree of 
pharyngeal occlusion varies, and the consequences can be more or less evident. Such consequences are primary snoring during sleep, increased upper airway resistance causing the individual to awaken, hypopnea with desaturation, and (in the case of full obstruction) apnea. Sleep-disordered breathing causes an increase in respiratory effort-related arousals, which disrupts sleep and results in nonrestorative sleep, excessive daytime sleepiness, fatigue, decreased libido, migraines, mood disorders including anxiety, lack of concentration, irritability, apathy and symptoms of depression [8]. Obstructive sleep apnea syndrome (OSAS) is the most prevalent breathing disturbance in sleep, [9] which is defined as more than five episodes of apnea or hypopnea per hour of sleep, accompanied by symptoms of sleep disturbance. It is characterized by repetitive episodes of partial or complete upper airway obstruction [10, 11]. The etiology includes abnormalities in both the physiology and anatomy of the airway and associated facial structures [12]. Patients with OSAS have a narrower pharyngeal airway than normal persons because of fat infiltration, the weight of the soft tissue of the neck, or reduced pharyngeal muscle tone [13]. Prevalence of OSAS ranges from $2 \%$ to $26 \%$ in adults [14]. The syndrome is 2 fold more in males, probably due to anatomical and functional gender-related reasons, like distribution of body fat [15]. Also obesity is probably associated with OSAS [16, 17]. Among women, OSAS is more frequent in the postmenopausal period, probably due to a hormonal influence on the physiopathology of upper airway obstruction during sleep [18]. Incidence of OSAS peaks in those between the ages of 50 and 60 [19]. Partial upper airway obstruction, even without apnea, results in awakenings and is designated upper airway resistance syndrome, which is characterized by excessive daytime sleepiness and more than five respiratory effort-related arousals per hour. This syndrome includes individuals whose apnea-hypopnea index is lower than five events per hour, with no significant oxygen saturation drop. The prevalence of upper airway resistance syndrome is similar among males and females, and the mean age of patients is approximately 30 [19]. Obstructive sleep apnea syndrome is associated with significant morbidity, including excessive daytime sleepiness, loud snoring during sleep, shortening of rapid eye movement sleep phases, daytime hypersomnolence, refractory hypertension, gastroesophageal reflux and impaired quality of life [20, 21]. Cardiovascular derangements, such as hypertension, arrhythmias, ST depression, loss of circadian variation, and rise of blood pressure may affect the individual's ability to work and possibly lead to a higher risk of stroke and myocardial infarction [22].

Except for diffuse musculoskeletal pain and pain at tender points, the symptoms reported by patients with SDB are similar to those of patients with FMS [23]. Patients with OSAS can also present FMS, however SDB, narcolepsy, and leg movement disorders are considered as uncommon causes of medically unexplained fatigue or pain syndromes [24-26]. It is also considered that patients with chronic fatigue syndrome and FMS have similar sleep structures [27].
STOP Questionnaire is a self-administered scale that includes four yes/no questions (snoring, fatigue, apnea and hipertension) which was developed to identify the patients with OSAS without using polysomnography or airway examinations, and it was found effective [17]. STOP-Bang test was derived from STOP Questionnaire to improve the sensitivity of the STOP Questionnaire to detect most patients with OSAS, especially moderate and severe ones. It is an alternative scoring model combining BMI, age, neck circumference, and gender with the STOP Questionnaire [17]. Answering yes to 3 or more items indicates high risk level for OSAS. Sensitivity of this test is more than STOP Questionnaire [17].

The main aim of this study was to evaluate the probable correlation between symptom severity of fibromyalgia (Fibromyalgia Impact Questionnaire-FIQ score) and STOP-Bang test which evaluates the risk level for OSAS. Also we tried to analyse the correlations among some subscales of FIQ and STOP-Bang that ask common symptoms, pain and fatigue.

\section{Materials and Methods}

Sixty Patients with the diagnosis of FMS were randomly selected by the computer. Patients $<18$ years old, who did not have magnetic resonance images (MRI) and written consents, were excluded. Thirty one of these 60 patients were included in the study. Accordance with the requirements of ethical standards (Helsinki Declaration), patients' informed consents were obtained. Demographic data including gender, age, body mass index and concomitant diseases are recorded. Physical examination including musculoskeletal and neurologic examination, measurement of neck circumference and limitation of cervical range of motion (ROM) were performed. Also MRI findings were recorded as decreased cervical lordosis, spondylosis and discopathy. STOP-Bang test which is commonly used for evaluating the risk level of obstructive sleep apnea was applied to all patients [17]. Beside this test presence of snoring and fatigue were asked again separately. For evaluating the impact of fibromyalgia a reliable and valid instrument- Fibromyalgia Impact Questionnaire (FIQ) was applied to all patients [28, 29]. Results of FIQ including total score, visual analog scale for pain (VAS pain, $10 \mathrm{~cm}$ ) and fatigue (VAS fatigue, $10 \mathrm{~cm}$ ) were recorded for each individual.

Statistical analysis was performed with SPSS 16.0 software package. For comparing the variables providing the assumption of normality t-test was used and for variables not providing the assumption of normality Mann-Whitney $U$ test was used. For categorical variables chi-square test was used. For analyzing correlation Spearman's correlation test was used because of the limited sample size and non-normal distributions. A value between 0 and 0.25 was accepted as 'no or poor', $0.26-0.50$ as 'moderate', $0.51-0.75$ as 'good', and $0.76-1.00$ as a 'very good' correlation. P values less than 0.05 were considered statistically significant. 


\section{Results}

Twenty five of 31 patients $(80,6 \%)$ were female and 6 patients $(19,4 \%)$ were male. There was no difference between female and male patients according to the means of continuous variables (age, BMI, VAS pain, VAS fatigue, and FIQ score), except the neck circumference. Neck circumference of male patients was significantly higher than the females $(p<0,05)$. Means of continuous variables and comparison of female and male patients according to the means are shown in Table 1.

All 31 patients $(100 \%)$ were complaining of fatigue, and most of them $(61,3 \%)$ reported snoring during sleep. According to the STOP-Bang test high risk of OSAS was found in $54,8 \%$ of the patients $(\mathrm{N}=17)$, while low risk of OSAS was found in $45,2 \%(\mathrm{~N}=14$, Table 2). Five of 6 male patients had high risk level of OSAS, whereas 12 of 25 female patients had high risk level of OSAS.

According to the MRI findings decreased cervical lordosis, spondylosis and discopathy were frequent among the patients
(74,2\%, 61,3\%, and 83,9\%, respectively). Examination of cervical ROM showed that limitation of extension and rotation was more frequent than the flexion (Table 2).

Table 1. Means of continuous variables and comparison of female and male patients according to the means $(N=31)$.

\begin{tabular}{lllll}
\hline & $\mathbf{N = 3 1}$ & $\begin{array}{l}\text { Female } \\
(\mathbf{N = 2 5})\end{array}$ & Male (N=6) & P value \\
\hline $\begin{array}{l}\text { Age (years) } \\
\text { BMI (kg/m2) }\end{array}$ & $47,97 \pm 11,40$ & $47,04 \pm 12,13$ & $51,83 \pm 7,13$ & 0,395 \\
$\begin{array}{l}\text { Neck } \\
\text { circumference }\end{array}$ & $33,54 \pm 2,73$ & $32,8 \pm 2,21$ & $36,66 \pm 2,58$ & $0,001^{*}$ \\
$\begin{array}{l}\text { (cm) } \\
\text { VAS pain }\end{array}$ & $5,58 \pm 2,17$ & $5,6 \pm 2,27$ & $5,5 \pm 1,87$ & 0,921 \\
VAS fatigue & $5,23 \pm 1,7$ & $5,24 \pm 1,8$ & $5,17 \pm 1,32$ & 0,927 \\
FIQ & $58,84 \pm 18,67$ & $58,92 \pm 19,31$ & $58,5 \pm 17,36$ & 0,962 \\
\hline
\end{tabular}

*Significance level: $\mathrm{p}<0,05$, BMI: body mass index, VAS: visual analog scale, FIQ: Fibromyalgia Impact Questionnaire score.

Table 2. Percents of discontinuous variables and comparison of female and male patients $(N=31)$.

\begin{tabular}{lllllllllllll}
\hline & N (percent) & & & & N (percent) & & \multicolumn{5}{c}{ N (percent) } \\
\hline MRI & Decreased lordosis & F & M & P value & Spondylosis & F & M & P value & Discopathy & F & M & P value \\
Positive & $23(74,2 \%)$ & 19 & 4 & 0,644 & $19(61,3 \%)$ & 16 & 3 & 0,534 & $26(83,9 \%)$ & 20 & 6 & 0,239 \\
Negative & $8(25,8 \%)$ & 6 & 2 & & $12(38,7 \%)$ & 9 & 3 & & $5(16,1 \%)$ & 5 & 0 & \\
ROM & Flexion & & & & Extension & & & & Rotation & & \\
Limitation & $8(25,8 \%)$ & 6 & 2 & 0,644 & $12(38,7 \%)$ & 8 & 4 & 0,124 & $14(45,2 \%)$ & 9 & 5 & $0,040 *$ \\
No limitation & $23(74,2 \%)$ & 19 & 4 & & $19(61,3 \%)$ & 17 & 2 & & $17(54,8 \%)$ & 16 & 1 \\
Test results & Snoring & & & & Fatigue & & & & STOP-Bang & & \\
Positive & $19(61,3 \%)$ & 16 & 3 & 0,534 & $31(100 \%)$ & 25 & 6 & 1,000 & $17(54,8 \%)$ & 12 & 5 & 0,124 \\
Negative & $12(38,7 \%)$ & 9 & 3 & & 0 & 0 & 0 & & $14(45,2 \%)$ & 13 & 1 \\
\hline
\end{tabular}

*Significance level: $\mathrm{p}<0,05$, MRI: magnetic resonance imaging, ROM: range of motion, F: female, M: male.

When we compared the females and males according to the discontinuous variables no significant difference was found for MRI findings, cervical flexion and extension, presence of snoring and fatigue, and STOP-bang test, except cervical rotation. Limitation of cervical rotation was significantly more frequent among male patients $(83,33 \%$ vs. $36 \%$, Table 2$)$. Concomitant diseases are shown in Table 3.

Table 3. Concomitant diseases $(N=31)$.

\begin{tabular}{ll}
\hline & N (percent) \\
\hline Hypertension & $5(16,1 \%)$ \\
Coronary artery disease & $1(3,2 \%)$ \\
Hypothyroidism & $4(12,9 \%)$ \\
Hypertension+ Hypothyroidism & $3(9,7 \%)$ \\
No concomitant disease & $18(58,1 \%)$ \\
\hline
\end{tabular}

Increasing age was found significantly correlated with high risk of OSAS (STOP-Bang test result) $(\mathrm{p}<0,05)$. Decreased cervical lordosis, cervical spondylosis, limitation of cervical extension and rotation were also found significantly correlated with increasing age $(p<0,01)$. Decreased cervical lordosis $(p<0,05)$, increasing age and neck circumference $(p<0,01)$ were found significantly correlated with increasing BMI (Table 4).

There was significant and positive correlation between snoring and VAS pain, VAS fatigue, FIQ score and high risk of OSAS $(p<0,01)$. Correlations between high risk of OSAS and VAS pain, VAS fatigue and FIQ score $(p<0,01)$ were significant, as well as the correlations between high risk of OSAS and limitation of cervical rotation, and presence of cervical discopathy and decreased cervical lordosis $(p<0,05)$. VAS pain was significantly correlated with VAS fatigue and FIQ score $(p<0,01)$, while VAS fatigue was also significantly correlated with FIQ score $(p<0,01$, Table 4$)$.

There was positive and significant correlation among limitations of cervical ROM $(p<0,01)$. Decreased cervical lordosis was found significantly correlated with limitation of cervical flexion $(p<0,01)$, extension $(p<0,05)$, and rotation $(p<0,01)$. Significant correlation was found between cervical spondylosis and limitation of cervical extension $(p<0,05)$ and decreased cervical lordosis $(p<0,01$, Table 4$)$. Statistically, correlations between presence of fatigue and other variables could not be calculated, because all patients were complaining of fatigue. 
Table 4. Spearman's rho correlation of variables $(N=31)$.

\begin{tabular}{|c|c|c|c|c|c|c|c|c|c|c|c|c|c|}
\hline & Age & BMI & Neck C & Snor & STOP-Bang & VAS p & VAS f & FIQ & Flex & Ext & Rot & Lord & Spon \\
\hline BMI & $\begin{array}{l}, 481 * * \\
, 006\end{array}$ & 1,000 & & & & & & & & & & & \\
\hline Neck C & $\begin{array}{l}, 328 \\
, 072\end{array}$ & $\begin{array}{l}, 537 * * \\
, 002\end{array}$ & 1,000 & & & & & & & & & & \\
\hline Snor & $\begin{array}{l}, 119 \\
, 525\end{array}$ & $\begin{array}{l}, 011 \\
, 953\end{array}$ & $\begin{array}{l}, 034 \\
, 857\end{array}$ & 1,000 & & & & & & & & & \\
\hline STOP-Bang & $\begin{array}{l}, 450 * \\
, 011\end{array}$ & $\begin{array}{l}, 164 \\
, 379\end{array}$ & $\begin{array}{l}, 195 \\
, 293\end{array}$ & $\begin{array}{l}, 477 * * \\
, 007\end{array}$ & 1,000 & & & & & & & & \\
\hline VAS p & $\begin{array}{l}, 121 \\
, 518\end{array}$ & $\begin{array}{l}, 216 \\
, 244\end{array}$ & $\begin{array}{l}, 266 \\
, 148\end{array}$ & $\begin{array}{l}, 855^{* *} \\
, 000\end{array}$ & $\begin{array}{l}, 573 * * \\
, 001\end{array}$ & 1,000 & & & & & & & \\
\hline VAS f & $\begin{array}{l}, 109 \\
, 561\end{array}$ & $\begin{array}{l}, 229 \\
, 215\end{array}$ & $\begin{array}{l}, 271 \\
, 141\end{array}$ & $\begin{array}{l}, 860 * * \\
, 000\end{array}$ & $\begin{array}{l}, 550 * * \\
, 001\end{array}$ & $\begin{array}{l}, 967 * * \\
, 000\end{array}$ & 1,000 & & & & & & \\
\hline FIQ & $\begin{array}{l}, 082 \\
, 662\end{array}$ & $\begin{array}{l}, 183 \\
, 324\end{array}$ & $\begin{array}{l}, 230 \\
, 214\end{array}$ & $\begin{array}{l}, 845^{* *} \\
, 000\end{array}$ & $\begin{array}{l}, 544 * * \\
, 002\end{array}$ & $\begin{array}{l}, 988^{* *} \\
, 000\end{array}$ & $\begin{array}{l}, 950 * * \\
, 000\end{array}$ & 1,000 & & & & & \\
\hline Flex & $\begin{array}{l}, 310 \\
, 090\end{array}$ & $\begin{array}{l}, 062 \\
, 740\end{array}$ & $\begin{array}{l}, 008 \\
, 964\end{array}$ & $\begin{array}{l}, 015 \\
, 938\end{array}$ & $\begin{array}{l}, 091 \\
, 627\end{array}$ & $\begin{array}{l}, 021 \\
, 911\end{array}$ & $\begin{array}{l}, 076 \\
, 686\end{array}$ & $\begin{array}{l}, 029 \\
, 877\end{array}$ & 1,000 & & & & \\
\hline Ext & $\begin{array}{l}, 519 * * \\
, 003\end{array}$ & $\begin{array}{l}, 152 \\
, 413\end{array}$ & $\begin{array}{l}, 301 \\
, 100\end{array}$ & $\begin{array}{l}, 088 \\
, 639\end{array}$ & $\begin{array}{l}, 322 \\
, 077\end{array}$ & $\begin{array}{l}, 165 \\
, 375\end{array}$ & $\begin{array}{l}, 075 \\
, 687\end{array}$ & $\begin{array}{l}, 141 \\
, 450\end{array}$ & $\begin{array}{l}, 742 * * \\
, 000\end{array}$ & 1,000 & & & \\
\hline Rot & $\begin{array}{l}, 588 * * \\
, 001\end{array}$ & $\begin{array}{l}, 153 \\
, 412\end{array}$ & $\begin{array}{l}, 232 \\
, 210\end{array}$ & $\begin{array}{l}, 189 \\
, 309\end{array}$ & $\begin{array}{l}, 433^{*} \\
, 015\end{array}$ & $\begin{array}{l}, 198 \\
, 285\end{array}$ & $\begin{array}{l}, 181 \\
, 330\end{array}$ & $\begin{array}{l}, 174 \\
, 349\end{array}$ & $\begin{array}{l}, 650 * * \\
, 000\end{array}$ & $\begin{array}{l}, 876^{* *} \\
, 000\end{array}$ & 1,000 & & \\
\hline Lord & $\begin{array}{l}, 599 * * \\
, 000\end{array}$ & $\begin{array}{l}, 389 * \\
, 031\end{array}$ & $\begin{array}{l}, 092 \\
, 622\end{array}$ & $\begin{array}{l}, 166 \\
, 372\end{array}$ & $\begin{array}{l}, 387 * \\
, 031\end{array}$ & $\begin{array}{l}209 \\
, 260\end{array}$ & $\begin{array}{l}, 214 \\
, 248\end{array}$ & $\begin{array}{l}, 161 \\
, 387\end{array}$ & $\begin{array}{l}, 495^{* * *} \\
, 005\end{array}$ & $\begin{array}{l}, 439^{*} \\
, 013\end{array}$ & $\begin{array}{l}, 502^{* * *} \\
, 004\end{array}$ & 1,000 & \\
\hline Spon & $\begin{array}{l}, 723 * * \\
, 000\end{array}$ & $\begin{array}{l}, 349 \\
, 054\end{array}$ & $\begin{array}{l}, 169 \\
, 363\end{array}$ & $\begin{array}{l}, 048 \\
, 797\end{array}$ & $\begin{array}{l}, 077 \\
, 679\end{array}$ & $\begin{array}{l}, 060 \\
, 748\end{array}$ & $\begin{array}{l}, 011 \\
, 952\end{array}$ & $\begin{array}{l}, 052 \\
, 782\end{array}$ & $\begin{array}{l}, 317 \\
, 082\end{array}$ & $\begin{array}{l}, 360 * \\
, 047\end{array}$ & $\begin{array}{l}, 322 \\
, 077\end{array}$ & $\begin{array}{l}, 469 * * \\
, 008\end{array}$ & 1,000 \\
\hline Disc & $\begin{array}{l}, 142 \\
, 445\end{array}$ & $\begin{array}{l}, 084 \\
, 655\end{array}$ & $\begin{array}{l}, 314 \\
, 086 \\
\end{array}$ & $\begin{array}{l}, 168 \\
, 365 \\
\end{array}$ & $\begin{array}{l}, 398^{*} \\
, 027\end{array}$ & $\begin{array}{l}, 238 \\
, 196 \\
\end{array}$ & $\begin{array}{l}, 215 \\
, 246\end{array}$ & $\begin{array}{l}260 \\
, 157\end{array}$ & $\begin{array}{l}142 \\
, 445 \\
\end{array}$ & $\begin{array}{l}, 012 \\
, 951\end{array}$ & $\begin{array}{l}, 045 \\
, 808\end{array}$ & $\begin{array}{l}, 012 \\
, 951\end{array}$ & $\begin{array}{l}, 058 \\
, 756\end{array}$ \\
\hline
\end{tabular}

* Significance level: $\mathrm{p}<0,05, * *$ Significance level: $\mathrm{p}<0,01, \mathrm{BMI}$ : body mass index, Neck C: neck circumference, Snor: snoring, VAS p: visual analog for pain, VAS f: visual analog for fatigue, FIQ: Fibromyalgia Impact Questionnaire score, Flex: limitation of cervical flexion, Ext: limitation of cervical extension, Rot: limitation of cervical rotation, Lord: decreased cervical lordosis, Spon: cervical spondylosis, Disc: cervical discopathy, Presence of fatigue was not calculated.

\section{Discussion}

In generalizing these results to other populations, one should take into account the selection bias, the lack of a control group and the small number of subjects. We recognize that none of the clinical examination findings alone are as objective as polysomnography in both diagnosing and determining the severity of OSAS but these examinations help us to think OSAS. Since the number of sleep centers in our country is small, it is still not widely performed. STOP-Bang test seems to be a useful co-examination for the clinics far from polysomnography.

Similar to the literature, female patients with FMS were 4 fold more than males in our study [30,31]. Mean age of our study group was over 48 . We thought that excluding patients $<$ 18 years old and patients without cervical MRI caused the increase of mean age. Mean BMI was over 28 and we explained this situation by the increasing age because, as stated in Table 4, BMI was significantly correlated with age. According to the STOP-Bang test BMI over 35 indicates high risk level for OSAS, and we found the mean of BMI as $28,03 \pm 4,72$. Neck circumference of male patients was significantly higher than the females probably due to anatomical and functional gender-related reasons, like distribution of body fat [15]. Also according to STOP-Bang test neck circumference over $40 \mathrm{~cm}$ indicates high risk level for OSAS, and mean neck circumference of our study group was lower than this $(33,54 \pm 2,73)$. Other items, except neck circumference and BMI may be the main determinants of the risk level for OSAS. Similar mean values for females and males given in Table 1 may show the homogenity of our randomly selected group. Also no significant difference was found for MRI findings, cervical flexion and extension, presence of snoring and fatigue, and STOP-bang test between female and male patients. Limitation of cervical extension was more frequent among males than females probably due to anatomical and functional gender-related reasons, like neck circumference and distribution of body fat. Most of our patients had no concomitant disease which can mimic OSAS.

In our patients, rates of presence of fatigue and snoring, and high risk of OSAS found by STOP-Bang test were very high. Fatigue is a common complaint for both patients with FMS and OSAS, so a high rate of $100 \%$ is not surprising for us [32]. But the amount of patients with high risk level of OSAS $(54,8 \%)$ found by STOP-Bang test was more than expected. In various studies with larger subject numbers, no association between FMS and SDB has been observed [33-36]. But the symptoms reported by patients with SDB are known to be similar to those of patients with FMS, except diffuse musculoskeletal pain and pain at tender points, so this may be the explanation of high rates [23]. There may be another explanation that patients with OSAS can also present FMS [7, 24-26, 37, 38]. We have to keep in mind that patients with FMS may have similar sleep structures to OSAS [27]. As 
emphasized in the literature the association is clear, although it does not imply a cause and effect relationship [7]. Number of female patients with high risk of OSAS $(\mathrm{N}=12)$ was more than males $(\mathrm{N}=5)$, but the rate was insignificantly higher in male patients ( 5 of 6 patients vs. 12 of 25 patients). We can say that OSAS is more frequent among males than females [15].

Similar to the literature increasing age was found significantly correlated with high risk of OSAS [19]. However, decreased cervical lordosis, cervical spondylosis, limitation of cervical extension and rotation were also found significantly correlated with increasing age as well as the significant correlation between increasing BMI and decreased cervical lordosis, increasing age and neck circumference. But significant and moderate correlations between high risk of OSAS and limitation of cervical rotation, and presence of cervical discopathy and decreased cervical lordosis were found. Positive and significant correlations among limitations of cervical ROM and cervical pathologies were not surprising, and we may predict that limitations of cervical ROM and cervical pathologies may lead to OSAS [39, 40]. By the increasing age, presence of decreased cervical lordosis, spondylosis and discopathy increases, so the high rates of these pathologies found by MRI can be related to higher mean age of our patients.

There was moderate and significant correlation between presence of snoring and positive STOP-Bang test. Also correlations among STOP-Bang test, VAS pain, VAS fatigue and FIQ score, and correlations among presence of snoring, VAS pain, VAS fatigue and FIQ score were similar. In busy clinics, maybe only asking presence of snoring can substitute for STOP-Bang test to refer these patients for the examination of upper airways.

\section{Conclusion}

Although it does not imply a cause and effect relationship, as emphasized in the literature the association between FMS and OSAS is clear. Physicians should keep in mind the presence of OSAS among patients with FMS, especially in male patients. Fatigue is the common symptom of both FMS and OSAS which can lead to misdiagnose. None of the clinical examination findings alone are as objective as polysomnography; however STOP-Bang test is an effective co-examination to predict the risk level of OSAS. Correlation between snoring and STOP-Bang test may show that only asking presence of snoring can substitute for STOP-Bang test to refer these patients for the examination of upper airways.

\section{References}

[1] Wolfe F, Smythe HA, Yunus MB et al. The American College of Rheumatology 1990 criteria for the classification of fibromyalgia. Report of the multicenter criteria committee. Arthritis Rheum 1990; 33 (2): 160-72.

[2] Mease P. Fibromyalgia syndrome: review of clinical presentation, pathogenesis, outcome measures, and treatment. J Rheumatol 2005; 75: 6-21.
[3] Ozgocmen S. New strategies in evaluation of therapeutic efficacy in fibromyalgia syndrome. Curr Pharm Des 2006; 12: 67-71.

[4] Bennett RM, Jones J, Turk DC, Russell IJ, Matallana L. An internet survey of 2,596 people with fibromyalgia. BMC Musculoskel Disord 2007; 8: 27.

[5] Hamilton NA, Affleck G, Tennen H, Karlson C, Luxton D, Preacher KJ, et al. Fibromyalgia: The role of sleep in affect and in negative event reactivity and recovery. Health Psychol 2008; 27: 490-7.

[6] Moldofsky H, Inhaber NH, Guinta DR, Alvarez-Horine SB. Effects of Sodium Oxybate on Sleep Physiology and Sleep/Wake-related Symptoms in Patients with Fibromyalgia Syndrome: A Double-blind, Randomized, Placebo-controlled Study. J Rheumatol 2010; 37: 2156-66.

[7] Germanowicz D, Lumertz MS, Martinez D, Margarites AF. Sleep disordered breathing concomitant with fibromyalgia syndrome. J Bras Pneumol 2006; 32 (4): 333-8.

[8] Caples SM, Gami AS, Somers VK. Obstructive sleep apnea. Ann Intern Med 2005; 142 (3): 187-97.

[9] Kryger MH. Diagnosis and management of sleep apnea syndrome. Clin Cornerstone 2000; 2: 39-47.

[10] Hui DSC, Ko FWS, Chu ASY, et al. Cephalometric assessment of craniofacial morphology in Chinese patients with obstructive sleep apnoea. Resp Med 2003; 97: 640-6.

[11] Yucel A, Unlu M, Haktanir A, Acar M, Fidan F. Evaluation of the Upper Airway Cross-sectional Area Changes in Different Degrees of Severity of Obstructive Sleep Apnea Syndrome: Cephalometric and Dynamic CT Study. AJNR Am J Neuroradiol 2005; 26: 2624-9.

[12] Battagel JM, Johal A. A cephalometric comparison of normal weight and obese subjects with obstructive sleep apnoea. Radiography 2000; 6: 283-92.

[13] Suratt PM, Dee P, Atkinson RL, et al. Fluoroscopic and computed tomographic features of the pharyngeal airway in obstructive sleep apnea. Am Rev Respir Dis 1983; 127: 487-92.

[14] Young T, Hutton R, Finn L, Badr S, Palta M. The gender bias in sleep apnea diagnosis: Are women missed because they have different symptoms? Arch Intern Med 1996; 156: 2445-51.

[15] Whittle AT, Marshall I, Mortimore IL, Wraith PK, Sellar RJ, Douglas NJ. Neck soft tissue and fat distribution: comparison between normal men and women by magnetic resonance imaging. Thorax 1999; 54 (4): 323-8.

[16] Frey WC, Pilcher J. Obstructive sleep-related breathing disorders in patients evaluated for bariatric surgery. Obes Surg 2003; 13: 676-83.

[17] Chung F, Yegneswaran B, Liao P, Chung SA, Vairavanathan S, Islam S, Khajehdehi A, Shapiro CM. STOP Questionnaire A Tool to Screen Patients for Obstructive Sleep Apnea. Anesthesiology 2008; 108: 812-21.

[18] Flemons WW. Obstructive sleep apnea. N Engl J Med 2002; 347 (7): 498-504.

[19] Bao G, Guilleminault C. Upper airway resistance syndrome-one decade later. Curr Opin Pulm Med 2004; 10 (6): 461-7. 
[20] Turkington PM, Sircar M, Allgar V, Elliott MW. Relationship between obstructive sleep apnoea, driving simulator performance, and risk of road traffic accidents. Thorax 2001; 56: $800-5$

[21] Shahar E, Whitney CW, Redline S, Lee ET, Newman AB, Javler F, George N, O'Connor T, Boland LL, Schwartz JE, Samet JM. Sleep-disordered breathing and cardiovascular disease: Cross-sectional results of the sleep heart health study. Am J Respir Crit Care Med 2001; 163: 19-25.

[22] Jager L, Gunther E, Gauger J, Reiser M. Fluoroscopic MR of the Pharynx in Patients with Obstructive Sleep Apnea. AJNR Am J Neuroradiol 1998; 19: 1205-14.

[23] Gold AR, Dipalo F, Gold MS, O'Hearn D. The symptoms and signs of upper airway resistance syndrome: a link to the functional somatic syndromes. Chest 2003; 123 (1): 87-95.

[24] Rizzi M, Sarzi-Puttini P, Sergi M. Alterazioni del sonno in corso di síndrome fibromialgica. Progressi in Reumatologia 2001; 2 (1): 60-8.

[25] Sepici V, Tosun A, Kokturk O. Obstructive sleep apnea syndrome as an uncommon cause of fibromyalgia: a case report Rheumatol Int 2007; 28 (1): 69-71.

[26] May KP, West SG, Baker MR, Everett DW. Sleep apnea in male patients with the fibromyalgia syndrome. Am J Med 1993; 94(5): 505-8.

[27] Togo F, Natelson BH, Cherniack NS, FitzGibbons J, Garcon C, Rapoport DM. Sleep structure and sleepiness in chronic fatigue syndrome with or without coexisting fibromyalgia. Arthritis Research \& Therapy 2008; 10 (3): R56.

[28] Burckhardt CS, Clark SR, Bennett RM. The Fibromyalgia impact questionnaire: development and validation. J Rheumatol 1991; 18: 728-33.

[29] Sarmer S, Ergin S, Yavuzer G. The validity and reliability of the Turkish version of the Fibromyalgia Impact Questionnaire. Rheumatol Int 2000; 20: 9-12.

[30] Abad V, Sarinas P, Guilleminault C. Sleep and rheumatologic disorders. Sleep Med Rev 2008; 12: 211-28.
[31] Wolfe F, Ross K, Anderson J, Russell IJ, Hebert L. The prevalence and characteristics of fibromyalgia in the general population. Arthritis Rheum 1995; 38 (1): 19-28.

[32] White KP, Speechley M, Harth M, Ostbye T. The London Fibromyalgia epidemiology study: comparing the demographic and clinical characteristics in 100 random community cases of Fibromyalgia versus controls. J Rheumatol 1999; 26: 1577-85.

[33] Alvarez Lario B, Teran J, Alonso JL, Alegre J, Arroyo I, Viejo JL. Lack of association between fibromyalgia and sleep apnea syndrome. Ann Rheum Dis 1992; 51(1): 108-11.

[34] Plantamura A, Steinbauer J, Eisinger J. Sleep apnea and fibromyalgia: the absence of correlation does not indicate an exclusive central hypothesis. Rev Med Interne 1995; 16 (9): $662-5$.

[35] Donald F, Esdaile JM, Kimoff JR, Fitzcharles MA. Musculoskeletal complaints and fibromyalgia in patients attending a respiratory sleep disorders clinic. J Rheumatol 1996; 23 (9): 1612-6.

[36] Sergi M, Rizzi M, Braghiroli A, Puttini PS, Greco M, Cazzola $\mathrm{M}$ et al. Periodic breathing during sleep in patients affected by fibromyalgia syndrome. Eur Respir J 1999; 14 (1): 203-8.

[37] Gold AR, Dipalo F, Gold MS, Broderick J. Inspiratory airflow dynamics during sleep in women with fibromyalgia. Sleep 2004; 27 (3): 459-66.

[38] Molony RR, MacPeek DM, Schiffman PL, Frank M, Neubauer JA, Schwartzberg $M$ et al. Sleep, sleep apnea and the fibromyalgia syndrome. J Rheumatol 1986; 13 (4): 797-800.

[39] Guilleminault C, Li KK, Philip P, Kushida CA. Anterior cervical spine fusion and sleep disordered breathing. Neurology 2003; 61 (1): 97-9.

[40] Goh HK, Li YH. Non-traumatic acute paraplegia caused by cervical disc herniation in a patient with sleep apnoea. Singapore Med J 2004; 45 (5): 235-8. 